\title{
Value of chest computed tomography scan in diagnosis of COVID-19; a systematic review and meta-analysis
}

\author{
Hasti Hossein ${ }^{1} \cdot{\text { Kosar Mohamed } \text { Ali }^{2} \cdot \text { Mostafa Hosseini }^{3} \cdot \text { Arash Sarveazad }^{4,5} \cdot \text { Saeed Safari }}^{6,7}$. \\ Mahmoud Yousefifard ${ }^{1}$
}

Received: 7 August 2020 / Accepted: 6 September 2020 / Published online: 12 October 2020

(c) Italian Association of Nuclear Medicine and Molecular Imaging 2020

\begin{abstract}
Purpose Real-time polymerase chain reaction (RT-PCR) and chest computed tomography (CT) scan are main diagnostic modalities of coronavirus disease 2019 (COVID-19). However, there is still no consensus on which of these methods is superior to the other. Therefore, the present meta-analysis was designed to answer to the question whether CT scan can be used in diagnosis of COVID-19 or not.

Methods Searches were performed in Medline, Embase, Scopus, and Web of Science databases until the end of April 2020. Two researchers gathered the data of diagnostic accuracy studies that had attempted to evaluate sensitivity and specificity of CT scan in diagnosis of COVID-19.

Results Data of 9 studies were included. Area under the curve of ground glass opacity (GGO), consolidation, pleural effusion, other CT features, and simultaneous observation of GGO with other CT features was 0.64 (95\% CI 0.60-0.69), 0.30 (95\% CI 0.26-0.34), 0.60 (95\% CI 0.56-0.64), 0.61 (95\% CI 0.56-0.65), and 0.90 (95\% CI 0.87-0.92), respectively. Sensitivity and specificity of simultaneous observation of GGO with other CT scan features was higher than all of the other signs. Sensitivity, specificity, and diagnostic odds ratio of this sign was calculated to be $0.90,0.89$, and 20 , respectively.

Conclusion Simultaneous observation of GGO and other features of viral pneumonia in CT scan had optimum performance in detection of COVID-19. However, it is suggested to make the final diagnosis based on both CT scan and RT-PCR, as none of the two diagnostic modalities are reliable alone.
\end{abstract}

Keywords COVID-19 · Severe acute respiratory syndrome coronavirus $2 \cdot$ Tomography X-ray computed · Polymerase chain reaction

Electronic supplementary material The online version of this article (https://doi.org/10.1007/s40336-020-00387-9) contains supplementary material, which is available to authorized users.

Saeed Safari

safari266@gmail.com

$\triangle$ Mahmoud Yousefifard

yousefifard.m@iums.ac.ir

Hasti Hossein

hastihossein@ymail.com

Kosar Mohamed Ali

kosarmohammadali@gmail.com

Mostafa Hosseini

mhossein110@yahoo.com

Arash Sarveazad

arashsarveazad@gmail.com

1 Physiology Research Center, Iran University of Medical Sciences, Hemmat highway, Tehran, Iran
2 College of Medicine, University of Sulaimani, Sulaimani, Iraq

3 Department of Epidemiology and Biostatistics, School of Public Health, Tehran University of Medical Sciences, Tehran, Iran

4 Colorectal Research Center, Iran University of Medical Sciences, Tehran, Iran

5 Nursing Care Research Center, Iran University of Medical Sciences, Tehran, Iran

6 Proteomics Research Center, Shahid Beheshti University of Medical Sciences, Tehran, Iran

7 Department of Emergency Medicine, Shohadye Tajrish Hospital, Shahid Beheshti University of Medical Sciences, Tajrish Squared, Tehran, Iran 


\section{Introduction}

Coronavirus disease 2019 (COVID-19), which is caused by infection with severe acute respiratory syndrome coronavirus-2 (SARS-CoV-2), is now known as a global pandemic that has affected millions of people. The speed at which this disease spread was so high that within 4 months of the initial reports of the disease in Wuhan, China, it was dispersed all around the world [1]. Statistics are indicative of the death of about $15 \%$ of those affected, most of which are individuals with old age. However, mortality among young people is also considerable [2].

One of the ways to control the disease is identifying contagious people. In the literature, real-time polymerase chain reaction (RT-PCR) has been introduced as the best diagnostic method [3]. However, this test is costly and time-consuming and is also associated with a large number of false negative results. In addition, the skill of the person obtaining the sample and the time interval between manifestation of the symptoms and performing the test affect RT-PCR findings $[4,5]$. Therefore, it cannot yet be said that RT-PCR is the gold standard for detection of COVID-19. These limitations have inspired some studies to suggest performing chest computed tomography (CT) scan. CT scan results are prepared faster that RT-PCR and this is an advantage of CT scan [5].

However, CT scan also has limitations, among which are its dependence on the skill of the radiologist [6] as well as its need for sterilizing the device after each time of using it for patients suspected to COVID-19. On the other hand, still no consensus has been reached on the diagnostic accuracy of CT scan in diagnosis of COVID-19. Therefore, the present systematic review was designed with the aim of gathering all the existing evidence on the diagnostic accuracy of chest CT scan in COVID-19 to find out if CT scan could be used for diagnosis of COVID-19 or not.

\section{Methods}

\section{Study design and search strategy}

PICO in the present systematic review is as follows: problem (P): COVID-19 disease; index test (I): chest CT scan; comparison (C): RT-PCR findings as reference test, and objective $(\mathrm{O})$ : accuracy of chest $\mathrm{CT}$. To reach the aims of the study, searches were performed in Medline (via PubMed), Embase, Scopus and Web of Science databases until the end of April 2020. Keywords including words related to COVID-19 and chest CT scan were selected. For finding keywords, Mesh and Emtree sections of Medline and Embase databases were searched. In the next step, the titles and abstracts of related articles were studied and finally, with the guidance of a specialist in the field of respiratory illnesses, the keywords were finalized. The search strategy is presented in appendix 1 .

In addition, a manual search was performed in preprint databases as well as searches via Google and Google Scholar search engines so that unpublished articles were also included in the study. In addition, by evaluating citation tracking and reference tracking, we attempted to find studies that could have been missed in the systematic search.

\section{Inclusion criteria}

In the present systematic review, diagnostic accuracy studies performed on chest CT scan in identification of COVID19 cases were included. Both retrospective and prospective studies were evaluated. Exclusion criteria consisted of lack of a group without COVID-19, case-series and case-report studies performed on confirmed COVID-19 patients, not reporting sensitivity and specificity or true positive (TP), false positive (FP), true negative (TN), and false negative (FN) cases, and review studies.

\section{Data gathering and quality control}

Initially, 2 independent researchers evaluated the records found. These 2 researchers assessed titles and abstracts of the studies and evaluated the full texts of potentially relevant studies to determine if they met the selection criteria. Finally, they summarized the studies in a checklist, individually. The checklist consisted of the following information: name of the first author, year of publication, study design, sample size, number of COVID-19 and non-COVID-19 patients, mean age, sex distribution, chest CT scan features for diagnosis of COVID-19, reference standard, CT findings interpreter, and TP, TN, FP, and FN. Any disagreement was resolved through discussion with a third researcher.

Quality assessment of the studies was performed based on the instructions suggested by quality assessment of diagnostic accuracy studies (QUADAS-2) [7].

\section{Statistical analyses}

All analyses were performed using STATA 14.0 statistical software. The analyses were performed using "midas" command. Data were recorded as TP, TN, FP, and FN and the output of the statistical software was reported as summary of receiver operating characteristics curve (SROC), sensitivity, specificity, diagnostic likelihood ratio and diagnostic odds ratio with $95 \%$ confidence interval (CI). Heterogeneity between the studies was evaluated using I 2 test; and due to presence of significant heterogeneity, random effect model 
was used. Deeks' funnel plot asymmetry test was applied for evaluating publication bias. The majority of studies had assessed the value of CT scan in diagnosis of COVID-19 based on CT scan features. Therefore, analyses were stratified for this variable. In all analyses, $p<0.05$ was considered statistically significant.

\section{Results}

\section{Characteristics}

The performed search yielded 339 non-duplicate articles. By evaluating the full texts of these articles, finally, 9 articles were included in the present systematic review [5, 6, 8-14] (Fig. 1).

6 studies were performed on the Chinese population, 1 study was on data from Italy, 1 study was performed in Japan and 1 study was done in the United States. 7 studies were retrospective cohorts. These studies included the data of 1942 patients suspected to COVID-19 (999 patients with COVID-19 and 943 Non-COVID-19 individuals). The most important $\mathrm{CT}$ features evaluated in the studies were ground-glass opacity (GGO), mixed GGO, consolidation, pleural effusion, air bronchogram, centrilubular nodules, and thickened interlobar septa. The gold standard was RT-PCR in 8 studies and follow-up of patients until the time of definite diagnosis in 1 study. Evaluation of CT scan findings was done by radiologists in all the studies. Table 1 shows a summary of the included studies.

One study had assessed the performance of 7 radiologists, separately, and another had compared the performance of 2 radiologists in identifying COVID-19 based on the findings of CT scan. Data of these articles were reported separately, based on the evaluation results of each radiologist. In Table 2, TP, TN, FP, and FN results described by the studies have been reported based on the interpreting radiologist as well as CT scan feature.

\section{Risk of bias assessment}

Since the design of 8 studies was retrospective cohort/ case-control, the risk of bias was considered to be high regarding patient selection. In addition, the flow and timing status was unclear in 3 studies. Finally, risk of bias and applicability of reference standard was unclear in 1 study as the final diagnosis of COVID-19 was said to be done based on follow-up (Fig. 2 and Table 3).

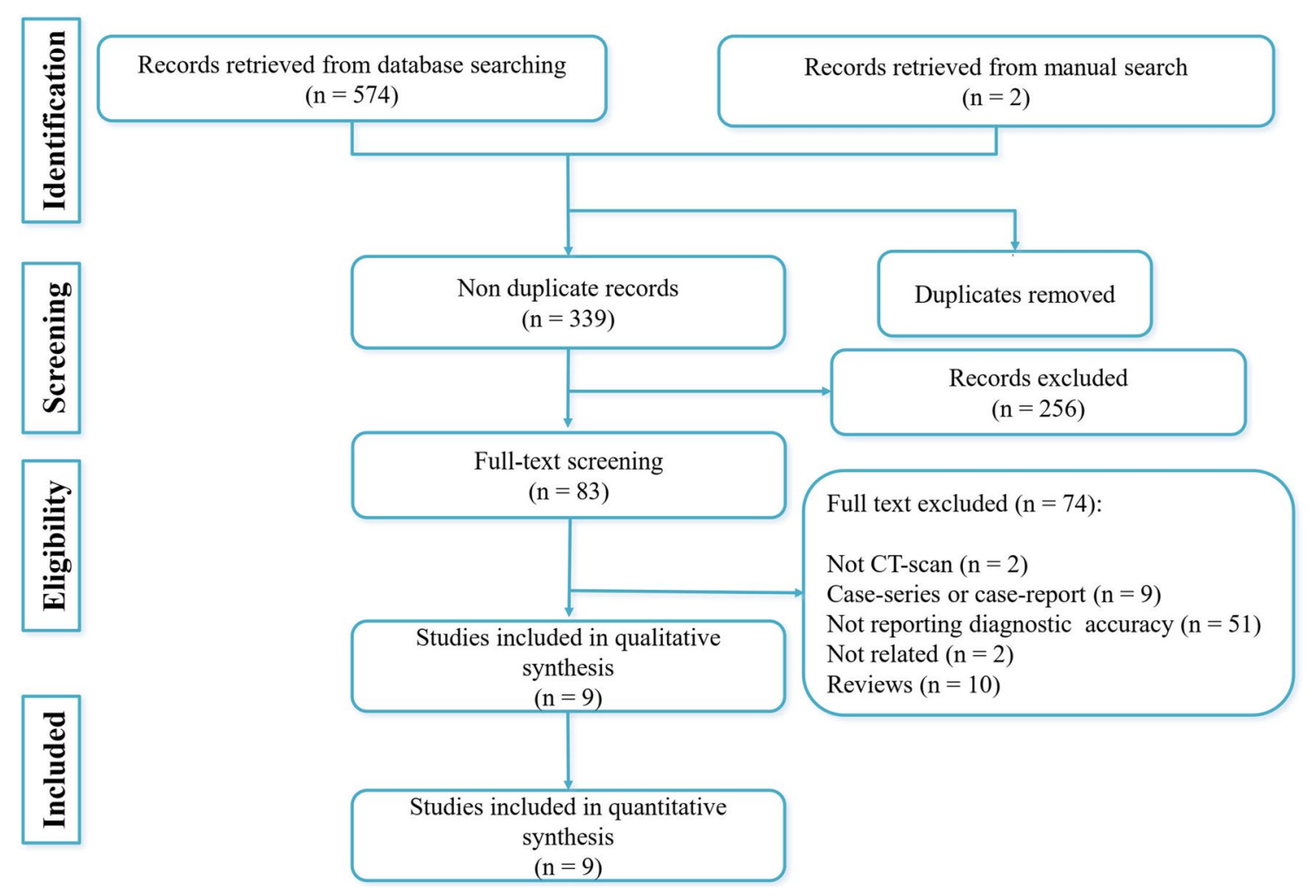

Fig. 1 Flow diagram of the present meta-analysis 
Table 1 Summary of included studies

\begin{tabular}{|c|c|c|c|c|c|c|c|c|c|}
\hline $\begin{array}{l}\text { Author; year; } \\
\text { country }\end{array}$ & Study type & Sample size & $\begin{array}{l}\text { Number of } \\
\text { COVID19 }\end{array}$ & $\begin{array}{l}\text { Number } \\
\text { of non- } \\
\text { COVID-19 }\end{array}$ & Mean age & $\begin{array}{l}\text { Number } \\
\text { of males }\end{array}$ & $\begin{array}{l}\text { CT features for } \\
\text { diagnosis }\end{array}$ & Gold standard & CT interpreter \\
\hline $\begin{array}{r}\text { Ai T; 2020; } \\
\text { China [8] }\end{array}$ & RCS & 1014 & 601 & 413 & 51 & 467 & $\begin{array}{l}\text { GGO, Con- } \\
\text { solidation, } \\
\text { reticulation/ } \\
\text { thickened } \\
\text { interlobar } \\
\text { septa, nod- } \\
\text { ules }\end{array}$ & RT-PCR & Radiologist \\
\hline $\begin{array}{l}\text { Bai H; 2020; } \\
\text { China / USA } \\
\text { [6] }\end{array}$ & RCS & 424 & 219 & 205 & 54.42 & 222 & $\begin{array}{l}\text { GGO, Mixed } \\
\text { GGO, Con- } \\
\text { solidation, } \\
\text { reticulation/ } \\
\text { thickened } \\
\text { interlobar } \\
\text { septa, nod- } \\
\text { ules }\end{array}$ & RT-PCR & $\begin{array}{c}\text { Seven separate } \\
\text { radiologists }\end{array}$ \\
\hline $\begin{array}{l}\text { Caruso D; } \\
\text { 2020; Italy } \\
\text { [9] }\end{array}$ & PCS & 158 & 62 & 96 & 57 & 83 & $\begin{array}{l}\text { Peripherally } \\
\text { GGO with } \\
\text { multilobe } \\
\text { and posterior } \\
\text { involvement, } \\
\text { bilateral } \\
\text { distribution, } \\
\text { and subseg- } \\
\text { mental vessel } \\
\text { enlargement } \\
\text { (>3 mm) }\end{array}$ & RT-PCR & Radiologist \\
\hline $\begin{array}{l}\text { Cheng Z; } \\
\text { 2020; China } \\
\text { [10] }\end{array}$ & RCS & 33 & 11 & 22 & 45.84 & 15 & $\begin{array}{l}\text { GGO, Mixed } \\
\text { GGO, Con- } \\
\text { solidation, } \\
\text { Air broncho- } \\
\text { gram, } \\
\text { Centrilubular } \\
\text { nodules, } \\
\text { Reticular } \\
\text { pattern }\end{array}$ & RT-PCR & Radiologist \\
\hline $\begin{array}{l}\text { Himoto Y; } \\
\text { 2020; Japan } \\
\text { [11] }\end{array}$ & RCS & 21 & 6 & 15 & 63.8 & 12 & $\begin{array}{l}\text { GGO-predom- } \\
\text { inant lesion, } \\
\text { Bilateral } \\
\text { GGO- } \\
\text { predominant } \\
\text { lesion, } \\
\text { GGO- and } \\
\text { peripheral } \\
\text { predominant } \\
\text { lesion }\end{array}$ & RT-PCR & $\begin{array}{r}\text { Two separate } \\
\text { radiologists }\end{array}$ \\
\hline $\begin{array}{l}\text { Long C; 2020; } \\
\text { China [5] }\end{array}$ & RCS & 87 & 36 & 51 & 46.1 & 46 & $\begin{array}{l}\text { GGO, Con- } \\
\text { solidation, } \\
\text { GGO with } \\
\text { consolida- } \\
\text { tion, Pleural } \\
\text { effusion, } \\
\text { presence } \\
\text { of GGO or } \\
\text { Consolida- } \\
\text { tion }\end{array}$ & $\begin{array}{l}\text { Repeated RT- } \\
\text { PCR }\end{array}$ & Radiologist \\
\hline
\end{tabular}


Table 1 (continued)

\begin{tabular}{|c|c|c|c|c|c|c|c|c|c|}
\hline $\begin{array}{l}\text { Author; year; } \\
\text { country }\end{array}$ & Study type & Sample size & $\begin{array}{l}\text { Number of } \\
\text { COVID19 }\end{array}$ & $\begin{array}{l}\text { Number } \\
\text { of non- } \\
\text { COVID-19 }\end{array}$ & Mean age & $\begin{array}{l}\text { Number } \\
\text { of males }\end{array}$ & $\begin{array}{l}\text { CT features for } \\
\text { diagnosis }\end{array}$ & Gold standard & CT interpreter \\
\hline $\begin{array}{l}\text { Yang H; 2020; } \\
\text { China [12] }\end{array}$ & RCS & 55 & 13 & 42 & 29.8 & 0 & $\begin{array}{l}\text { GGO, Patch- } \\
\text { like shadow, } \\
\text { Fiber } \\
\text { Shadow, } \\
\text { Pleural effu- } \\
\text { sion }\end{array}$ & $\begin{array}{l}\text { Final diagnosis } \\
\text { based on fol- } \\
\text { low up }\end{array}$ & NR \\
\hline $\begin{array}{l}\text { Zhao D; 2020; } \\
\text { China [13] }\end{array}$ & CCS & 34 & 19 & 15 & 42.2 & 17 & $\begin{array}{l}\text { Multiple } \\
\text { mottling and } \\
\text { GGO }\end{array}$ & RT-PCR & Radiologist \\
\hline $\begin{array}{l}\text { Zhu W; 2020; } \\
\text { China [14] }\end{array}$ & RCS & 116 & 32 & 84 & 40 & 56 & $\begin{array}{l}\text { GGO, Con- } \\
\text { solidation, } \\
\text { Pleural effu- } \\
\text { sion }\end{array}$ & RT-PCR & Radiologist \\
\hline
\end{tabular}

$C C S$ case-control study, $C T$ computed tomography, $G G O$ ground glass opacity, $N R$ not reported, $P C S$ prospective cohort study, $R C S$ retrospective cohort study, $R T-P C R$ real-time polymerase chain reaction

\section{Meta-analysis}

Analyses were stratified according to type of CT feature. On this basis, AUCs of GGO alone, consolidation, pleural effusion, other CT features, and GGO with other CT features were found to be 0.64 (95\% CI $0.60-0.69$ ), 0.30 (95\% CI $0.26-0.34), 0.60$ (95\% CI $0.56-0.64), 0.61$ (95\% CI $0.56-0.65)$, and 0.90 (95\% CI $0.87-0.92)$, respectively (Fig. 3 and Table 4).

Diagnostic performance of CT features in diagnosis of COVID-19 has been reported in Table 4. Overall, sensitivity and specificity of GGO with other CT features was higher than all of the other signs. Sensitivity and specificity of this sign were 0.90 and 0.89 , respectively. It should be noted that diagnostic odds ratio of GGO with other features was calculated to be 20 , which was significantly higher than all of the other signs (Figs. 4 and 5).

\section{Publication bias}

In Fig. 6, publication bias was assessed based on CT features. The findings shown in this figure confirm that there is no publication bias in evaluation of the diagnostic value of CT features in diagnosis of COVID-19.

\section{Discussion}

The present meta-analysis attempted to evaluate the diagnostic value of CT scan in detection of patients with COVID-19 for the first time. Analyses showed that the only reliable sign for diagnosis of COVID-19 via CT scan is the simultaneous presence of GGO and other features of viral pneumonia. However, the presence of each of these signs alone does not have acceptable diagnostic value for screening positive cases. Sensitivity and specificity of GGO with other features of viral pneumonia in diagnosis of COVID-19 were calculated to be $90 \%$ and $89 \%$, respectively.

Although the overall analysis of the present study is indicative of the acceptable value of CT scan in detection of COVID-19, we should not forget about the differences in skills and abilities of radiologists. For instance, the study by Bai et al. evaluated the performance of 7 radiologists in diagnosis of COVID-19 based on CT scan findings. The results of the study showed that the sensitivity calculated for interpretation by these radiologists ranged from 70 to 97\%. In addition, the specificities reported for CT scan in the study ranged from 24 to 100\% [6]. Therefore, the diagnostic value of CT scan in diagnosis of COVID-19 is largely dependent on the experience and skill of the interpreter.

In the majority of the studies, the gold standard for definitive diagnosis of COVID-19 was RT-PCR. However, the diagnostic value of RT-PCR has been questioned in some studies. For example, Li et al. retrospectively evaluated 610 patients with suspected COVID-19 and showed that there was a considerable number of false negative cases in RTPCR evaluation. In addition, the performance of this test depends on the number of days passing from the onset of symptoms and in a considerable portion of people there is a need for serial evaluations to confirm the presence of 
Table 2 Summary of CT scan findings in patients with suspected COVID-19

\begin{tabular}{|c|c|c|c|c|c|c|}
\hline Author; year; country & CT features for diagnosis & CT interpreter & $\mathrm{TP}$ & FP & FN & $\mathrm{TN}$ \\
\hline Ai T; $[8]$ & GGO, Consolidation, reticulation/thickened interlobar septa, nodules & Radiologist & 580 & 308 & 21 & 105 \\
\hline \multirow[t]{7}{*}{ Bai H; [6] } & \multirow[t]{7}{*}{ GGO, Mixed GGO, Consolidation, reticulation/thickened interlobar septa, nodules } & Radiologist 1 & 158 & 13 & 62 & 192 \\
\hline & & Radiologist 2 & 157 & 24 & 62 & 181 \\
\hline & & Radiologist 3 & 206 & 156 & 13 & 49 \\
\hline & & Radiologist 4 & 28 & 0 & 2 & 28 \\
\hline & & Radiologist 5 & 25 & 2 & 5 & 26 \\
\hline & & Radiologist 6 & 22 & 3 & 8 & 26 \\
\hline & & Radiologist 7 & 21 & 0 & 9 & 28 \\
\hline Caruso D; [9] & $\begin{array}{l}\text { Peripherally GGO with multilobe and posterior involvement, bilateral distribution, } \\
\text { and subsegmental vessel enlargement }(>3 \mathrm{~mm})\end{array}$ & Radiologist & 60 & 45 & 2 & 54 \\
\hline \multirow[t]{6}{*}{ Cheng Z; [10] } & GGO & Radiologist & 11 & 20 & 0 & \\
\hline & Mixed GGO & & 7 & 16 & 4 & 6 \\
\hline & Consolidation & & 6 & 17 & 5 & 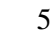 \\
\hline & Air bronchogram & & 8 & 6 & 3 & 16 \\
\hline & Centrilubular nodules & & 3 & 17 & 8 & 5 \\
\hline & Reticular pattern & & 9 & 5 & 2 & 17 \\
\hline \multirow[t]{10}{*}{ Himoto Y; [11] } & GGO-predominant lesion & Radiologist 1 & 6 & 7 & 0 & 8 \\
\hline & GGO- and peripheral predominant lesion & Radiologist 1 & 6 & 4 & 0 & 11 \\
\hline & Bilateral GGO- predominant lesion & Radiologist 1 & 6 & 5 & 0 & 10 \\
\hline & Bilateral GGO- and peripheral predominant lesion & Radiologist 1 & 6 & 4 & 0 & 11 \\
\hline & Bilateral GGO- and peripheral predominant lesion without other signs & Radiologist 1 & 4 & 1 & 2 & 14 \\
\hline & GGO-predominant lesion & Radiologist 2 & 5 & 6 & 1 & 9 \\
\hline & GGO- and peripheral predominant lesion & Radiologist 2 & 5 & 6 & 1 & 9 \\
\hline & Bilateral GGO- predominant lesion & Radiologist 2 & 5 & 5 & 1 & 10 \\
\hline & Bilateral GGO- and peripheral predominant lesion & Radiologist 2 & 5 & 6 & 1 & 9 \\
\hline & Bilateral GGO- and peripheral predominant lesion without other signs & Radiologist 2 & 5 & 3 & 1 & 12 \\
\hline \multirow[t]{5}{*}{ Long C; [5] } & GGO & Radiologist & 11 & 8 & 25 & 43 \\
\hline & Consolidation & & 6 & 22 & 30 & 29 \\
\hline & GGO with consolidation & & 19 & 21 & 17 & 39 \\
\hline & Pleural effusion & & 2 & 7 & 34 & 44 \\
\hline & Presence of GGO, Consolidation, or both & & 35 & 51 & 1 & 0 \\
\hline \multirow[t]{4}{*}{ Yang H; [12] } & GGO & NR & 6 & 26 & 7 & 16 \\
\hline & Patch-like shadow & & 5 & 15 & 8 & 27 \\
\hline & Fiber Shadow & & 3 & 3 & 10 & 39 \\
\hline & Pleural effusion & & 5 & 11 & 6 & 31 \\
\hline Zhao D; [13] & Multiple mottling and GGO & Radiologist & 17 & 1 & 2 & 14 \\
\hline \multirow[t]{3}{*}{ Zhu W; [14] } & GGO & Radiologist & 15 & 10 & 17 & 74 \\
\hline & Consolidation & & 4 & 7 & 28 & 77 \\
\hline & Pleural effusion & & 2 & 2 & 30 & 82 \\
\hline
\end{tabular}

$C T$ computed tomography, GGO ground glass opacity, $N R$ not reported, $T P$ true positive, $F P$ false positive, $T N$ true negative, $F N$ false negative 


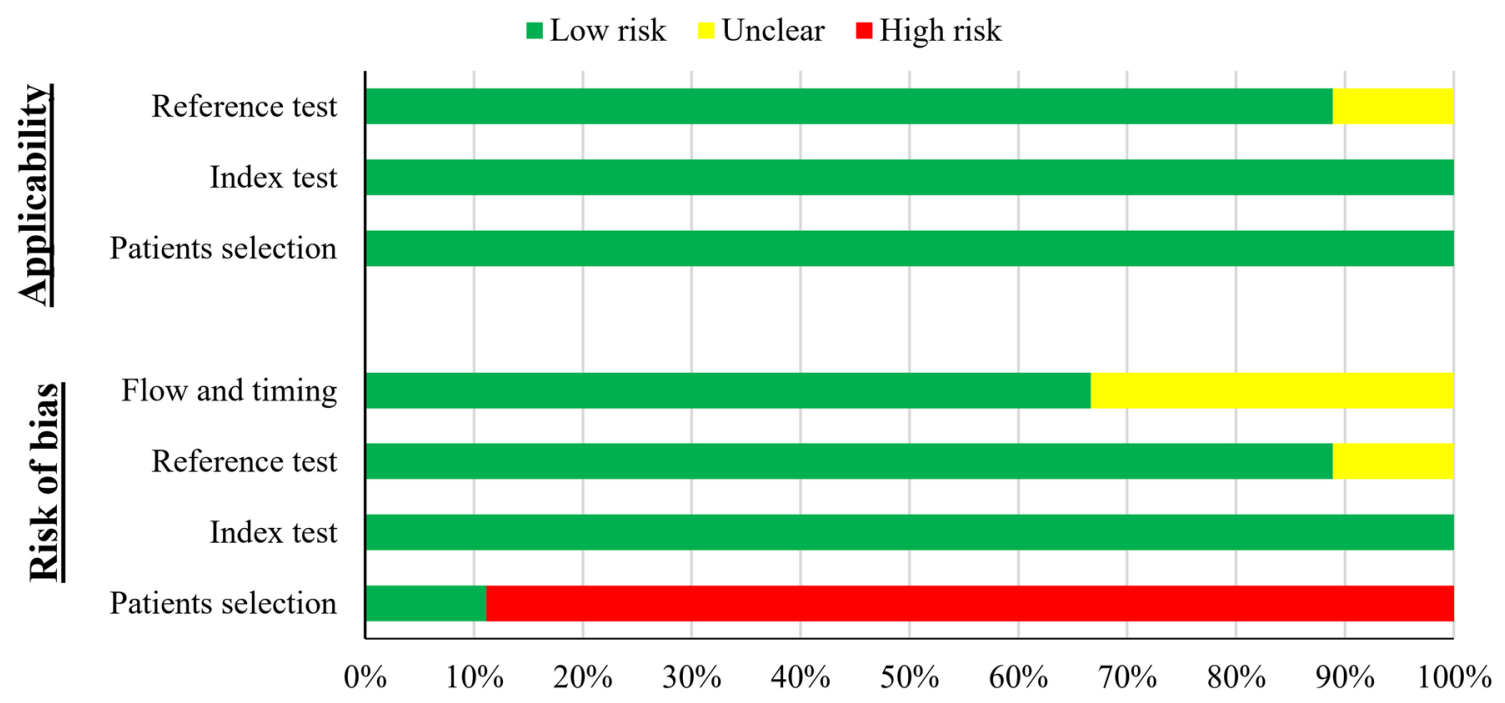

Fig. 2 Risk of bias assessment of included studies based on QUADAS-2 guideline

Table 3 Risk of bias assessment among included studies

\begin{tabular}{|c|c|c|c|c|c|c|c|}
\hline \multirow{2}{*}{ Study } & \multicolumn{4}{|l|}{ Risk of bias } & \multicolumn{3}{|l|}{ Applicability } \\
\hline & Patient selection & Index test & Reference test & Flow and timing & Patient selection & Index test & Reference test \\
\hline Ai T; 2020; China & : : & (:) & (:) & (:) & (:) & (:) & (;) \\
\hline Bai H; 2020; China / USA & : : & ;) & (:) & ;) & (:) & ;:) & (:) \\
\hline Caruso D; 2020; Italy & (-) & (:) & (-) & (:) & (;) & (-) & (:) \\
\hline Cheng Z; 2020; China & (:) & (-) & (:) & $\odot$ & (:) & (-); & (:) \\
\hline Himoto Y; 2020; Japan & :) & (:) & (:) & (:) & (:) & (:) & (:) \\
\hline Long C; 2020; China & : & ;) & (:) & $\odot$ & (:) & :-) & (:) \\
\hline Yang H; 2020; China & : $:$ & (;) & $\odot$ & $\odot$ & (:) & (-) & $\oplus$ \\
\hline Zhao D; 2020; China & :) & (-) & (:) & (-) & (:) & (-) & (:) \\
\hline Zhu W; 2020; China & :) & (-): & (:) & (-) & (:) & (-) & (:) \\
\hline
\end{tabular}

SARS-CoV-2. These researchers believe that the reason for these false negative results is the small number of viruses in some obtained samples, errors in measurement, and the limitations of sample transportation [4]. Also, in another study, Long et al. showed that the first RT-PCR performed has cases of false negative. Therefore, it is best that patients with abnormal findings in their CT scan be considered as probable COVID-19 cases and undergo serial RT-PCR evaluations [5].

Another imaging modality that can be used in diagnosis of COVID-19 is magnetic resonance imaging (MRI). The value of MRI in diagnosis and detection of lung diseases has been proven in previous studies [15-17]. Use of MRI for identifying COVID-19 patients has been suggested in existing studies. These studies believe that MRI is able to detect COVID-19-related cardiovascular complications. For example, in a study on patients recovering from COVID-19, Puntmann et al. found that $78 \%$ of patients had some degree of cardiac involvement, while $60 \%$ had myocardial infarction [18]. Another study found that sensitivity and specificity of MRI in identifying nodules after COVID-19 were $92.7 \%$ and $100 \%$, respectively. Therefore, these researchers concluded that MRI could be used as an alternative to CT scan [19]. However, MRI has its limitations. First, MRI equipment is not available in most health care facilities in developing countries, and second, it costs much more than a CT scan. Therefore, before making a recommendation to use MRI in suspected COVID-19 patients, its cost-effectiveness should be considered. 
GGO

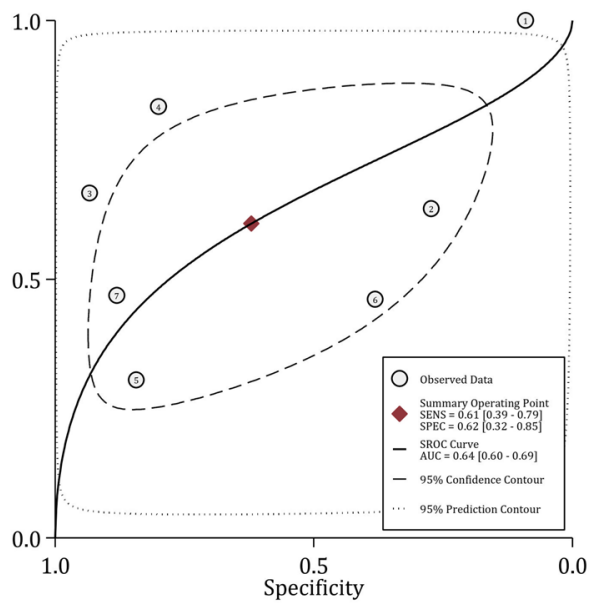

Pleural effusion

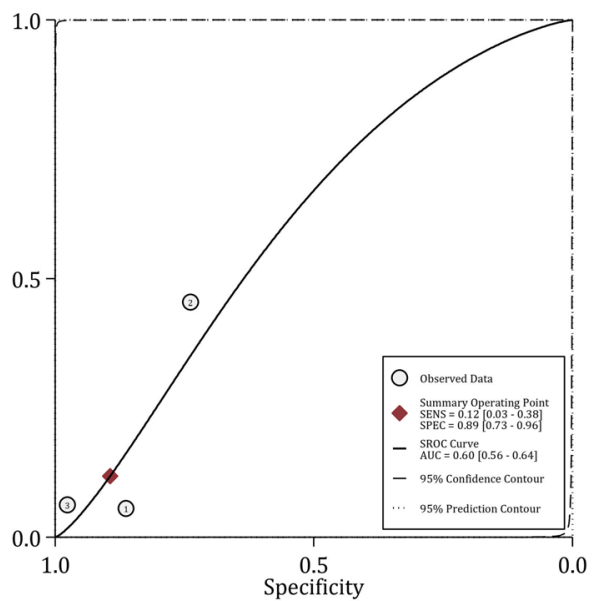

GGO with other CT features

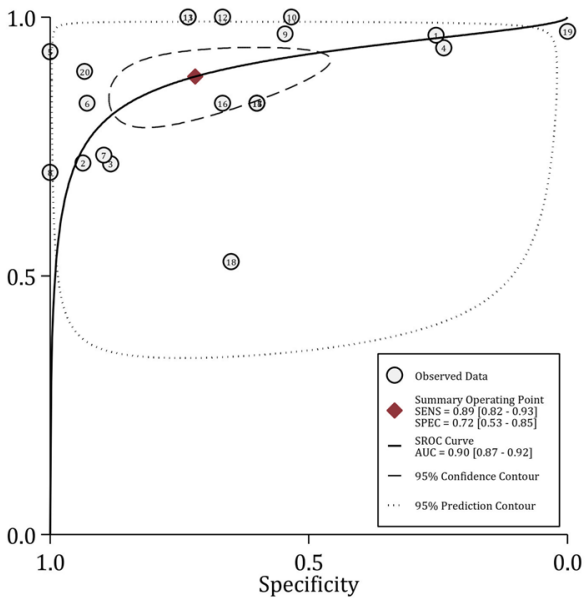

\section{Consolidation}

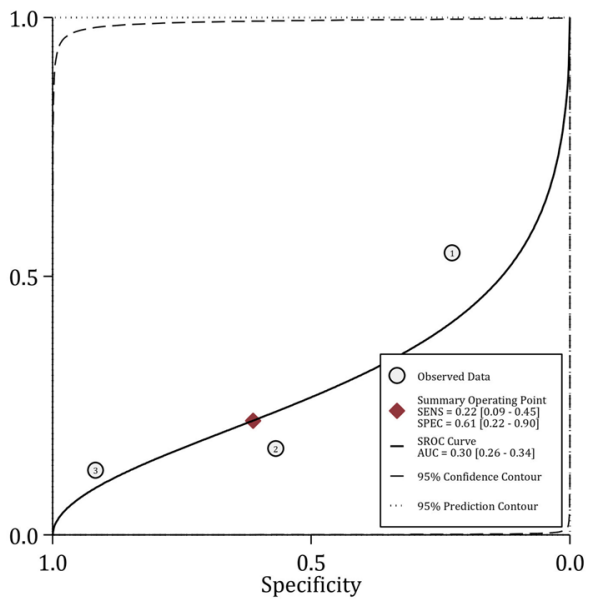

Other CT signs

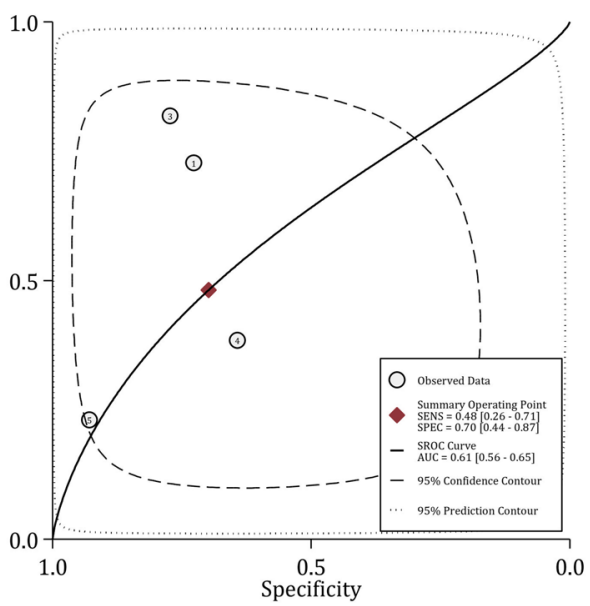


४Fig. 3 Summary receiver operating characteristics (SROC) of computed tomography (CT) findings in detection of SARS-CoV2 infection. AUC: Area under the curve; GGO: Ground glass opacity; SENS: Sensitivity; SPEC: Specificity; GGO with other features: GGO + Consolidation, GGO + pleural effusion, or GGO + other signs

One of the weak points of the included studies was that the time of performing CT scan had not been specified. It is not known how much time had passed from the onset of the symptoms when the CT scans were obtained. In 1 study they could be obtained on the first day of hospital admission and in another study, it could be performed on the next days. Therefore, the day on which CT scan was performed and its value was calculated is unknown in these studies, while its performance could change with time. This is also a limitation of the findings of the present study.

Another limitation observed among the studies was the retrospective nature of the majority of these studies. That is why in risk of bias assessment section, the risk of bias in patient selection was reported to be high in 8 studies. Therefore, prospective studies should better be carried out for evaluation of the diagnostic value of CT scan in diagnosis of COVID-19.
Obtaining results rapidly, determining the severity of the disease, and helping in choosing a treatment plan for the patients are among the strong points of CT scan, which cannot be achieved using PCR. In addition, PCR result is positive in many asymptomatic patients without any evidence of the disease on imaging. To sum all up, CT scan and PCR both have their own weak and strong points and it seems that they can complement each other for diagnostic evaluation of patients with suspected COVID-19, especially in those who are hospitalized. Of course, both of these modalities are tools that help the physician make a diagnosis and, in the end, it is the physician who will choose the best diagnostic modality based on clinical evidence, epidemiological status of the region he is managing, and other factors.

\section{Conclusion}

The findings of the present study showed that presence of GGO with other features of viral pneumonia in CT scan had a sensitivity and specificity of $90 \%$ and $89 \%$, respectively, in detection of cases with COVID-19. However, due to limitations such as not reporting the time interval

Table 4 Performance of CT scan in diagnosis of SARS-CoV2 infection based on CT features

\begin{tabular}{llllllll}
\hline CT features & $\begin{array}{l}\text { Number of } \\
\text { experi- } \\
\text { ments* }\end{array}$ & AUC (95\% CI) & $\begin{array}{l}\text { Sensitivity }(95 \% \\
\text { CI })\end{array}$ & $\begin{array}{l}\text { Specificity }(95 \% \\
\text { CI) }\end{array}$ & PLR (95\% CI) & NLR (95\% CI) & DOR (95\% CI) \\
\hline GGO & 7 & $0.64(0.60-0.69)$ & $0.61(0.39-0.79)$ & $0.62(0.32-0.85)$ & $1.6(0.8-3.1)$ & $0.63(0.39-1.02)$ & $3(1-7)$ \\
Consolidation & 3 & $0.30(0.26-0.34)$ & $0.22(0.09-0.45)$ & $0.61(0.22-0.90)$ & $0.6(0.3-1.0)$ & $1.27(0.77-2.09)$ & $0(0-1)$ \\
Pleural effusion & 3 & $0.60(0.56-0.64)$ & $0.12(0.03-0.38)$ & $0.89(0.73-0.96)$ & $1.1(0.4-2.8)$ & $0.99(0.87-1.12)$ & $1(0-3)$ \\
$\begin{array}{l}\text { Other sign } \\
\begin{array}{l}\text { GGO with other } \\
\text { features }\end{array}\end{array}$ & 5 & $0.61(0.56-0.65)$ & $0.48(0.26-0.71)$ & $0.70(0.44-0.87)$ & $1.6(0.6-4.1)$ & $0.74(0.41-1.35)$ & $2(0-2)$ \\
\hline
\end{tabular}

*There are different stratifications in the 6 included studies such as comparing the performance of different radiologists in detection of COVID19 patients and assessment of different CT features in diagnosis of SARS-CoV2 infection. Therefore, number of experiments is higher than the total number of included studies

${ }^{\#}$ GGO with other features: GGO + Consolidation, GGO + pleural effusion, or GGO + other

$A U C$ area under the receiver operating characteristics (ROC) curve, $C I$ confidence interval, $C T$ computed tomography, $G G O$ ground glass opacity, $N L R$ negative likelihood ratio, $P L R$ positive likelihood ratio, $D O R$ diagnostic odds ratio 

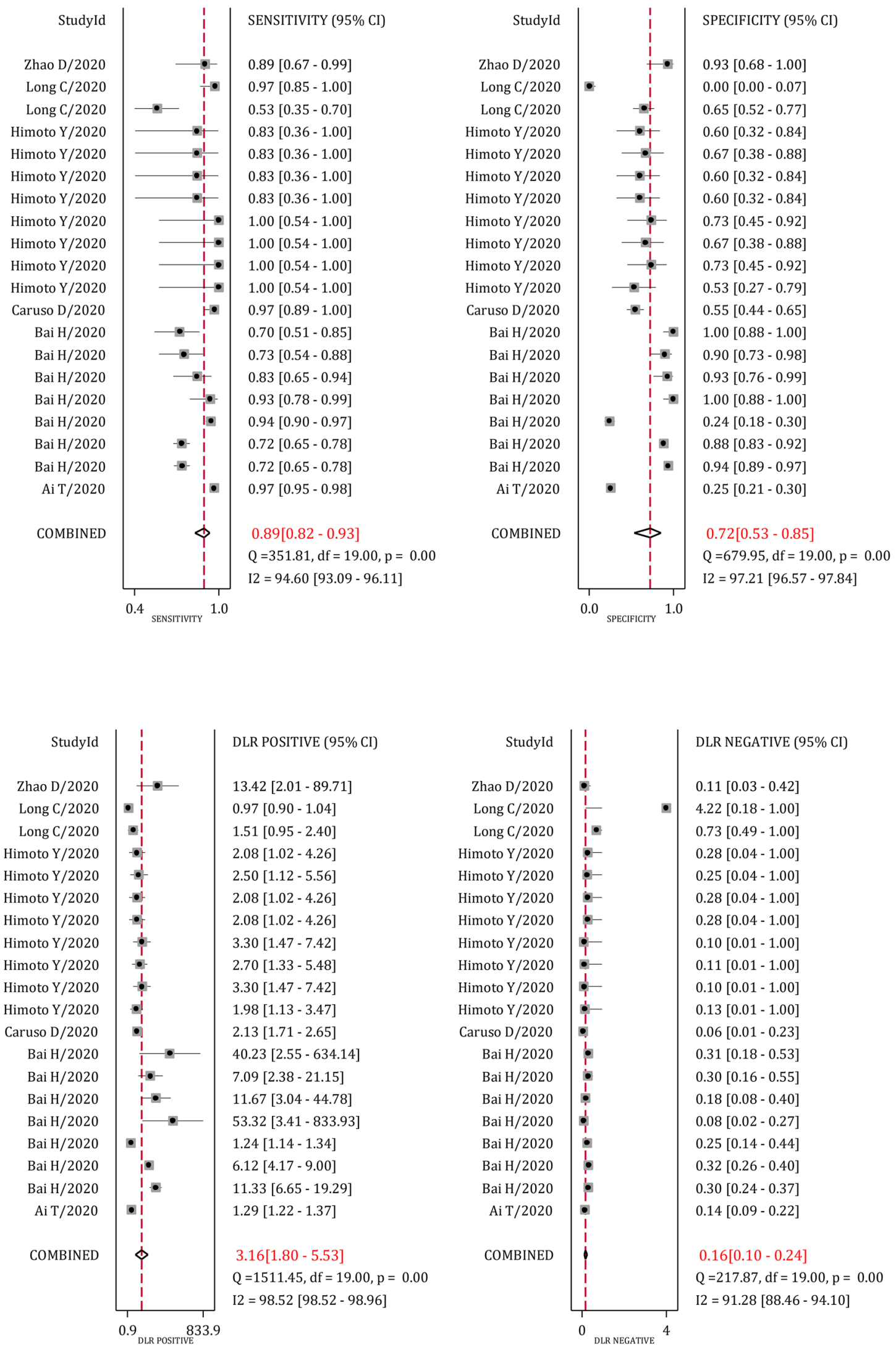
4Fig. 4 Sensitivity, specificity, and positive and negative diagnostic likelihood ratios (DLR) of ground glass opacity (GGO) with other features in computed tomography findings in detection of SARSCoV2 infection. \#, GGO with other features: GGO+Consolidation, $\mathrm{GGO}$ + pleural effusion, or GGO + other signs

between onset of symptoms and CT scan evaluation and using RT-PCR as the gold standard in these studies, we should be cautious in interpreting the findings. In addition, COVID-19 diagnosis based on CT scan is dependent on the skill and experience of the radiologist, which is a serious limitation for using CT scan for diagnosing the disease. On the other hand, existing evidence indicate the presence of numerous false negative cases in RT-PCR, requiring serial RT-PCR in some cases to reach a definitive diagnosis.

Therefore, it seems that both CT scan and RT-PCR have serious limitations in diagnosis of COVID-19 and relying on either of these 2 modalities alone for diagnosis of COVID19 could lead to misdiagnosis. Therefore, it is generally suggested to make the final diagnosis based on both CT scan and RT-PCR, as none of the 2 diagnostic modalities are reliable alone. Finally, serial evaluation of patients using these tests may increase their diagnostic accuracy.
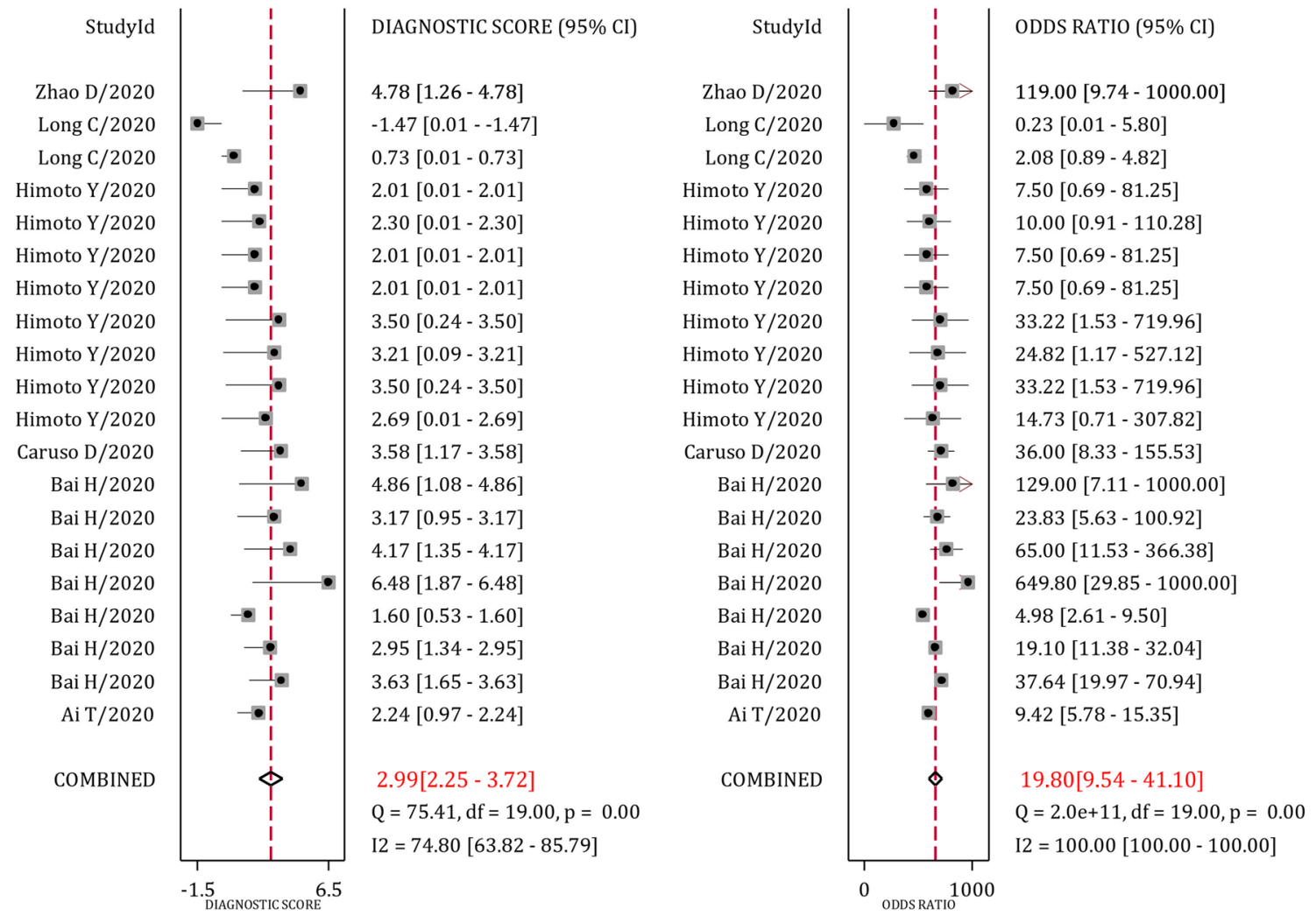

Fig. 5 Diagnostic score and diagnostic odds ratio of ground glass opacity (GGO) with other features in computed tomography findings in detection of SARS-CoV2 infection. GGO with other features: GGO + Consolidation, GGO + pleural effusion, or GGO + other signs 


\section{GGO}

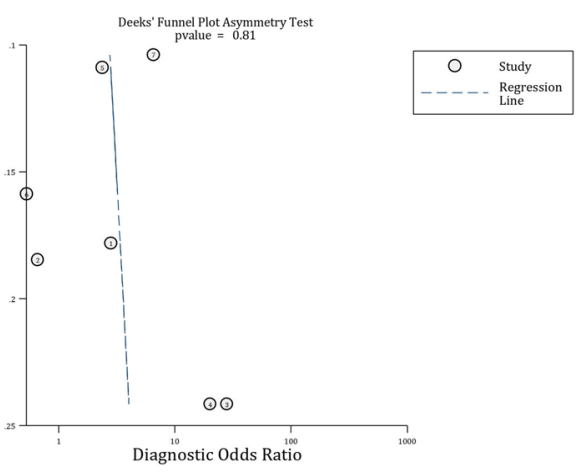

\section{Pleural effusion}

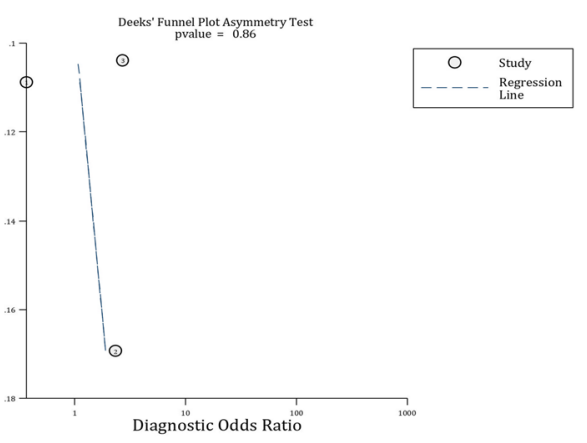

\section{GGO with other CT features}

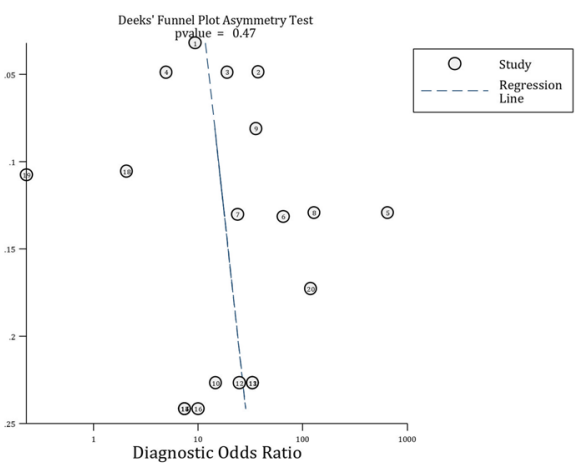

\section{Consolidation}

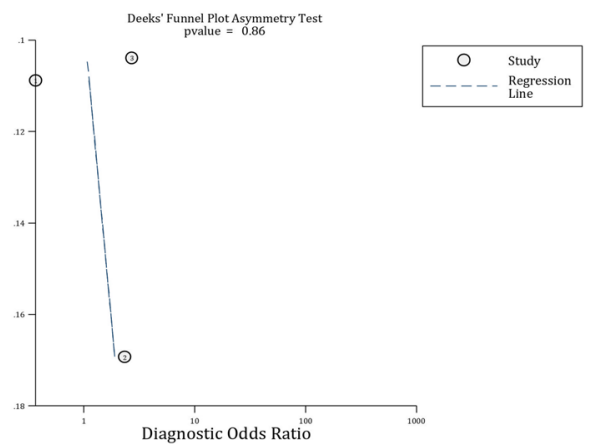

Other CT signs

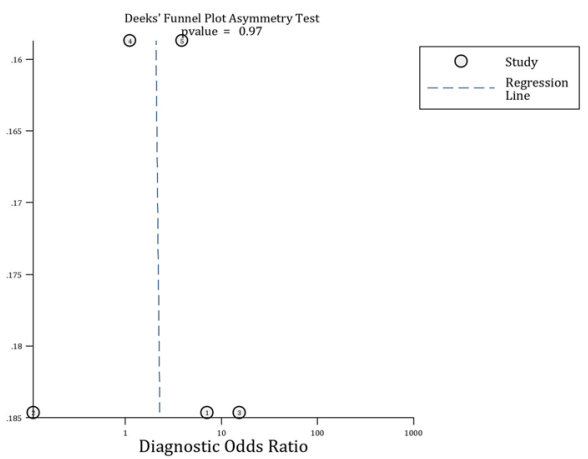

Fig. 6 Publication bias assessment based on computed tomography findings. GGO with other features: GGO + Consolidation, GGO + pleural effusion, or GGO + other signs

\section{Acknowledgements None.}

Author contributions Study design: MY, MH, SS, and KMA; search design and performing the search: SS and MY; data gathering: $\mathrm{HH}$, KMA, and MY; analysis: MH and SS; interpretation of results: all authors; drafting: MY and HH; Revising the paper: All authors.

Funding Iran University of Medical Sciences supported this study.

\section{Compliance with ethical standards}

Conflict of interest The authors declared that there is no conflict of interest.

Consent to participate This paper is a meta-analysis and obtaining consent to participate is not applicable.

Consent for publication This paper is a meta-analysis and consent for publication is not applicable. 
Ethical approval This study was approved by Ethics Committee of Iran University of Medical Sciences.

Availability of data and material All data used were presented in the tables and figures.

Code availability Not applicable.

\section{References}

1. Kolifarhood G, Aghaali M, Saadati HM, Taherpour N, Rahimi $\mathrm{S}$, Izadi $\mathrm{N}$ et al (2020) Epidemiological and clinical aspects of Covid-19; a narrative review. Archiv Acad Emerg Med 8(1):e41

2. Han X, Fan Y, Wan YL, Shi H (2020) A diabetic patient with 2019-nCoV infection who recovered and was discharged from hospital. J Thorac Imag 35(3):W94-W95

3. Mardani R, Vasmehjani AA, Zali F, Gholami A, Nasab SDM, Kaghazian $\mathrm{H}$ et al (2020) Laboratory Parameters in Detection of COVID-19 Patients with Positive RT-PCR; a Diagnostic Accuracy Study. Archiv Acad Emerg Med 8(1):e43

4. Li Y, Yao L, Li J, Chen L, Song Y, Cai Z et al (2020) Stability issues of RT-PCR testing of SARS-CoV-2 for hospitalized patients clinically diagnosed with COVID-19. J Med Virol 92:903-908

5. Long C, Xu H, Shen Q, Zhang X, Fan B, Wang C et al (2020) Diagnosis of the Coronavirus disease (COVID-19): rRT-PCR or CT? Eur J Radiol 126:108961

6. Bai HX, Hsieh B, Xiong Z, Halsey K, Choi JW, Tran TML, et al (2020) Performance of radiologists in differentiating COVID-19 from viral pneumonia on chest CT. Radiology. 200823

7. Whiting PF, Rutjes AW, Westwood ME, Mallett S, Deeks JJ, Reitsma JB et al (2011) QUADAS-2: a revised tool for the quality assessment of diagnostic accuracy studies. Ann Intern Med 155(8):529-536

8. Ai T, Yang Z, Hou H, Zhan C, Chen C, Lv W, et al (2020) Correlation of chest $\mathrm{CT}$ and $\mathrm{RT}$-PCR testing in coronavirus disease 2019 (COVID-19) in China: A report of 1014 cases. Radiology. 200642
9. Caruso D, Zerunian M, Polici M, Pucciarelli F, Polidori T, Rucci C, et al (2020) Chest CT features of COVID-19 in Rome, Italy. Radiology. 201237

10. Cheng Z, Lu Y, Cao Q, Qin L, Pan Z, Yan F et al (2020) Clinical Features and Chest CT Manifestations of Coronavirus Disease 2019 (COVID-19) in a Single-Center Study in Shanghai China. AJR Am J Roentgenol 215(1):121-126

11. Himoto Y, Sakata A, Kirita M, Hiroi T, Kobayashi KI, Kubo K et al (2020) Diagnostic performance of chest CT to differentiate COVID-19 pneumonia in non-high-epidemic area in Japan. Japanese J Radiol 38(5):400-406

12. Yang H, Sun G, Tang F, Peng M, Gao Y, Peng J et al (2020) Clinical features and outcomes of pregnant women suspected of coronavirus disease 2019. J infec 81(1):e40-e44

13. Zhao D, Yao F, Wang L, Zheng L, Gao Y, Ye J et al (2020) A comparative study on the clinical features of COVID-19 pneumonia to other pneumonias. Clin Infec Dis 71(15):756-761

14. Zhu W, Xie K, Lu H, Xu L, Zhou S, Fang S (2020) Initial clinical features of suspected coronavirus disease 2019 in two emergency departments outside of Hubei, China. Journal of medical virology. [In press]

15. Razek AA (2012) Diffusion magnetic resonance imaging of chest tumors. Cancer Imag 12(3):452-463

16. Razek AAKA, Elkammary S, Elmorsy AS, Elshafey M, Elhadedy $T$ (2011) Characterization of mediastinal lymphadenopathy with diffusion-weighted imaging. Magn Reson Imag 29(2):167-172

17. Razek AAKA, Gaballa G, Elashry R, Elkhamary S (2015) Diffusion-weighted MR imaging of mediastinal lymphadenopathy in children. Japanese J Radiol 33(8):449-454

18. Puntmann VO, Carerj ML, Wieters I, Fahim M, Arendt C, Hoffmann J, et al (2020) Outcomes of cardiovascular magnetic resonance imaging in patients recently recovered from coronavirus disease 2019 (COVID-19). JAMA Cardiol

19. Ates OF, Taydas O, Dheir H (2020) Thorax magnetic resonance imaging findings in patients with coronavirus disease (COVID19). Acad Radiol

Publisher's Note Springer Nature remains neutral with regard to jurisdictional claims in published maps and institutional affiliations. 